\title{
Large-scale patterns in community structure of benthos and fish in the Barents Sea
}

\author{
Edda Johannesen $^{1} \cdot$ Lis Lindal Jørgensen ${ }^{1} \cdot$ Maria Fossheim $^{1} \cdot$ Raul Primicerio $^{2}$ • \\ Michael Greenacre ${ }^{2,3} \cdot$ Pavel A. Ljubin ${ }^{4} \cdot$ Andrey V. Dolgov ${ }^{4}$ Randi B. Ingvaldsen ${ }^{1}$. \\ Natalya A. Anisimova ${ }^{4}$ Igor E. Manushin ${ }^{4}$
}

Received: 26 June 2015/Revised: 18 February 2016/Accepted: 12 April 2016/Published online: 23 April 2016

(c) The Author(s) 2016. This article is published with open access at Springerlink.com

\begin{abstract}
Biogeographical patterns have an ecological basis, but few empirical studies possess the necessary scale and resolution relevant for investigation. The Barents Sea shelf provides an ideal study area, as it is a transition area between Atlantic and Arctic regions, and is sampled by a comprehensive survey of all major functional groups. We studied spatial variation in species composition of demersal fish and benthos to elucidate how fish and benthos communities co-varied in relation to environmental variables. We applied co-correspondence analysis on presence-absence data of 64 fishes and 302 benthos taxa from 329 bottom trawl hauls taken at the Barents Sea ecosystem survey in August-September 2011. We found highly significant similarities in the spatial pattern of distribution of benthos and fishes, despite their differences in motility and other ecological traits. The first common ordination axis separated boreal species in the south-west (Atlantic temperate water) from Arctic species in the north-east (Arctic cold water, ice-covered in winter). The second common
\end{abstract}

Electronic supplementary material The online version of this article (doi:10.1007/s00300-016-1946-6) contains supplementary material, which is available to authorized users.

Edda Johannesen

eddaj@imr.no

1 Institute of Marine Research, P.O. Box 1870, 5817 Bergen, Norway

2 Faculty of Biosciences, Fisheries and Economics, UiT - The Arctic University of Norway, 9037 Troms $\varnothing$, Norway

3 Department of Economics and Business, Barcelona Graduate School of Economics, Universitat Pompeu Fabra, 08005 Barcelona, Spain

4 Knipovich Polar Research Institute of Marine Fisheries and Oceanography, 183038 Murmansk, Russia axis separated shallow bank species from species found in deep basins and trenches. Our results show that fish and benthos communities had a similar relationship to the environmental gradients at the scale of hundreds to thousands of kilometres. We further discussed how fish-benthos interactions vary between sub-regions in the Barents Sea based on species traits and a food web topology for the Barents Sea. This study forms a basis for further investigations on links between fish and benthos communities in the Barents Sea.

Keywords Community data $\cdot$ Multivariate analysis . Trawl survey $\cdot$ Ecosystem survey $\cdot$ Benthic fauna

\section{Introduction}

Few empirical studies possess the necessary scale and resolution to address the ecological basis for spatial patterns across scales from biogeography to local assemblages (Wiens 2011). It is well established that local abiotic conditions and ecological interactions shape the local assemblages (e.g. Cornell and Harrison 2013). However, even at the large spatial scale of biogeography, spatial patterns can have an ecological basis and be driven by adaptations to abiotic factors, as well as ecological interactions (Wiens 2011). These ecological factors could account for biogeographical barriers in the absence of clear physical obstacles to dispersal, as observed in the oceans.

The Barents Sea is a large marine ecosystem where more than 100 species of fish and 3000 species of invertebrates make up the fauna associated with the sea floor (Anisimova et al. 2011; Dolgov et al. 2011a). In the Barents Sea, the marine fauna belongs to two main zoogeographical groups, associated with either temperate Atlantic 
or cold Arctic water masses (Fig. 1). Recently, there have been large-scale studies $\left(\sim 1.5\right.$ million $\left.\mathrm{km}^{2}\right)$ identifying demersal fishes and megabenthos assemblages and relating these to abiotic factors (Anisimova et al. 2011; Dolgov et al. 2011a; Johannesen et al. 2012; Jørgensen et al. 2015). For both fishes and benthos, temperature and depth were found to be the most important structuring factors (Johannesen et al. 2012; Jørgensen et al. 2015). However, fishes and benthic invertebrates differ in many traits that can affect how the assemblages are structured in space. For example, adult stages of fishes and benthic invertebrates differ in motility, an important trait influencing spatial patterns. Furthermore, although the life forms of benthic invertebrates are much more diverse than those of fishes, they generally occupy lower trophic levels, often being the prey of fishes. Therefore, the community structures of fishes and megabenthos and their relationship to the environment might differ.

The joint spatial community structure and relationship to abiotic factors of demersal fishes and megabenthos have never been investigated in the Barents Sea. In other areas where fishes and benthic invertebrates have been studied together, similar associations with abiotic factors by fish and benthos have been interpreted as either similar responses to the environment, or as the aggregative response of benthivorous fishes on benthic invertebrate prey species (Gaertner et al. 1999; Colloca et al. 2003; Reiss et al. 2010; Sell and Kröncke 2013). However, most of these studies have been on a comparably smaller spatial scale.

Here we study demersal fishes and megabenthos spatial co-variation in relation to abiotic factors in the Barents Sea. We apply co-correspondence analysis (ter Braak 2004) to community data of fish and benthos caught in the same trawl hauls at a large-scale survey. We address the following questions:

1. Does species composition of fish and benthos co-vary in space?

2. Do the fish and benthos communities respond similarly to the same environmental variables?
Fig. 1 Barents Sea shelf (black square) and adjacent areas in the north-east Atlantic. Main inflows and currents influencing the oceanographic conditions in the Barents Sea are shown as arrows. Blue arrows Arctic water, red arrows Atlantic water and green arrows coastal inflow (modified from Loeng 1991)

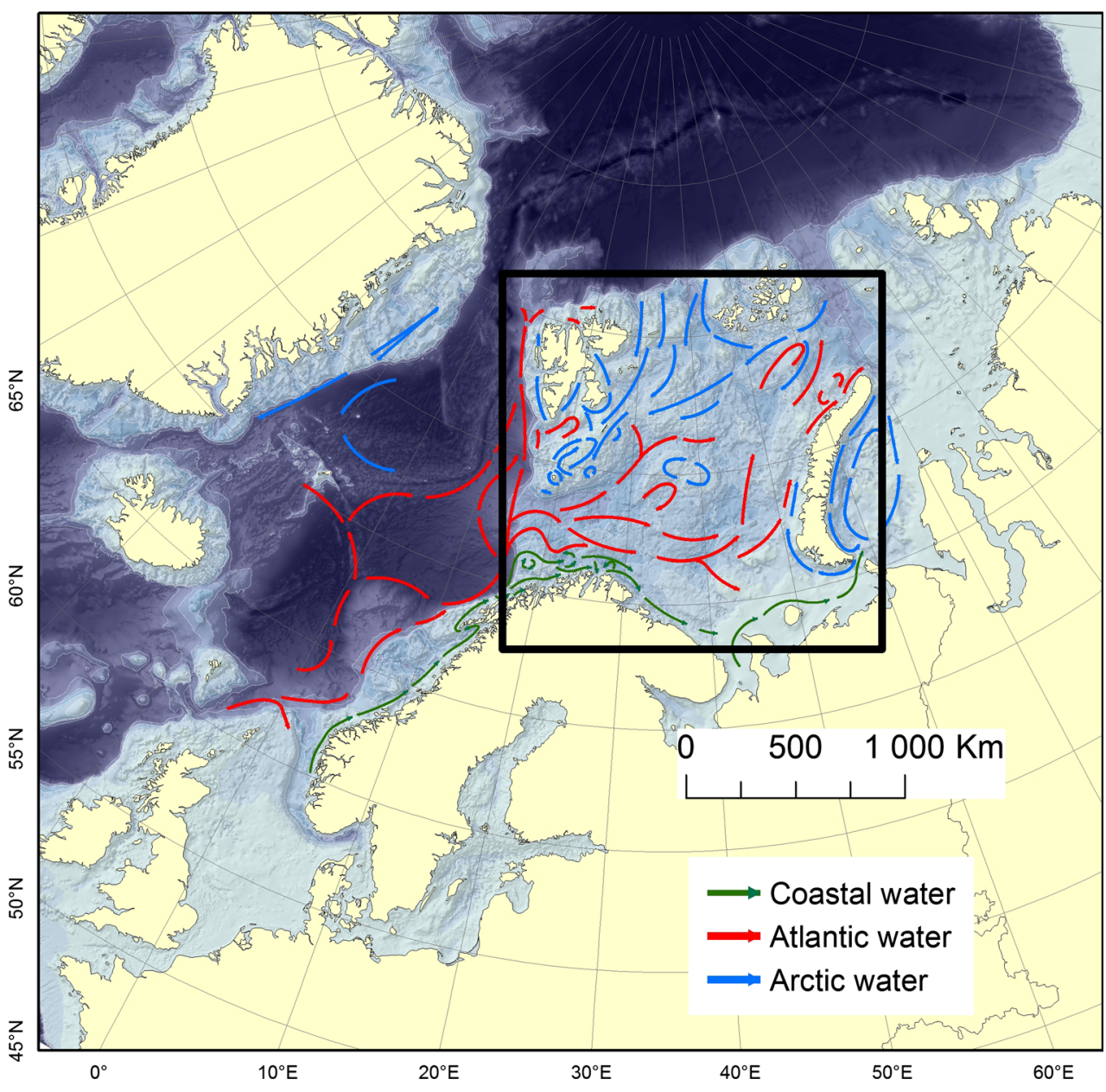




\section{Materials and methods}

\section{Community data}

In this paper, we use data from the joint IMR (Institute of Marine Research, Norway) and PINRO (Knipovich Polar Research Institute of Marine Fisheries and Oceanography, Russia) Barents Sea Ecosystem survey (Anon 2011; Michalsen et al. 2013). The survey covers the whole Barents Sea shelf. In 2011, the megabenthos species identification was sufficiently standardised to qualify to baseline mapping (Jørgensen et al. 2015) and to compare with the fish data. During the survey, a Campelen 1800 shrimp bottom trawl towed on double warps and a rockhopper ground gear was used throughout. The mesh size was $80 \mathrm{~mm}$ (stretched) in the front and $16-22 \mathrm{~mm}$ in the codend, allowing the capture and retention of small-sized fish and megabenthos. The trawl catches of fishes and megabenthos were sorted to the lowest possible taxonomic level on board (for details on species identification see Wienerroither et al. 2011; Jørgensen et al. 2015). The trawl configuration and bottom contact were monitored remotely by Scanmar trawl sensors. The standard towing time was $15 \mathrm{~min}$ at 3 knots, equivalent to a towing distance of 0.75 nautical miles $(1390 \mathrm{~m})$. We included 329 demersal trawl stations in our study. The standard distance between stations was $35 \mathrm{~nm}$ (about $65 \mathrm{~km}$ ).

Prior to the analysis, the data were pre-screened. Some groups were either recorded at genus level or higher, or pooled to a higher taxonomic level afterwards because their species identification was judged to be uncertain. Pelagic species, associated with the free water masses, do not belong to the demersal community and are poorly sampled by bottom trawls. They were excluded from our data. The resulting data set had 64 demersal fish taxa, hereafter only called "fish" (59 species and 5 groups at higher taxonomic levels), and 302 megabenthos taxa (187 species and 115 groups at higher taxonomic levels), hereafter only called "benthos" (Online Resource 1). Of these, 63 fish and 175 benthos taxa could be classified into zoogeographical groups based on Andriashev and Chernova (1995), Mecklenburg et al. (2013), for fishes, and Sirenko (2004, 2009), Vasilenko and Petryachov (2009), Buzhinskaja (2010), Sirenko and Denisenko (2010) and Stapanjants (2012) for benthic invertebrates (Online Resource 1).

\section{Environmental data}

We used the environmental variables ice, temperature, salinity and depth. Depth and temperature influence species composition of fish and benthos (Johannesen et al. 2012; Jørgensen et al. 2015). Temperature and salinity are used to distinguish different water masses in the Barents Sea. The presence of sea ice has a direct impact on the annual net primary production in the northern and eastern Barents Sea (Dalpadado et al. 2014). Additionally, in a sea ice dominated system, there is benthic fallout of ice algae (Cochrane et al. 2012).

Bottom depth was registered by depth sensors on the trawl for each bottom trawl station (depth contours are shown in Figs. 1, 2). Temperature and salinity at the bottom (measured $5 \mathrm{~m}$ above the sea floor) were measured with a Seabird conductivity, temperature and depth (CTD) profiler close to the trawl stations (Fig. 2). Sea ice data from SMMR and SSM/I passive microwave data were obtained from the National Snow and Ice Data Centre (Maslanik and Stroeve 1999; Meier et al. 2006). The data had a 25 by $25 \mathrm{~km}$ grid resolution. The total number of days with more than $15 \%$ ice concentration within the period 1 August 2010 to 31 July 2011 (ice presence) was assigned to each trawl station.

\section{Statistical analysis}

The statistical analyses of fish ( 329 stations by 64 taxa) and benthos (329 stations by 302 taxa) communities were conducted on presence-absence data. Although much information on community structure is lost when focusing on presence-absence data, the choice allows to avoid sources of uncertainty associated with sampling and skewed distributions of the biomass and abundance data. We retained rare species in the data set even though they were found to have little influence on the final outcome of the analysis (Greenacre 2013a).

Having data sets for two communities, one for fish and one for benthos, observed at the same sampling points, is ideal for the application of co-correspondence analysis (CoCA, ter Braak 2004). CoCA identifies the most important common axes in the two communities that maximise the co-variance between the station positions in the fish and benthos spaces. The species that contribute to these common axes are thus identified as strongly associated. The results of CoCA are two co-varying ordinations, one of the stations and fish taxa, and the other of the stations and the benthos taxa. In these ordinations, we used the contribution biplot scaling (Greenacre 2013b), where the more outlying species of fish and benthos are those that contribute most to the solution and thus to the co-variation. Added to each of the ordination biplots are the four standardised environmental variables: temperature, depth, ice presence and salinity. These are plotted using as coordinates their regression coefficients on the two axes of the respective ordinations. The environmental variables are supplementary variables, since they have not been used in 
(a)

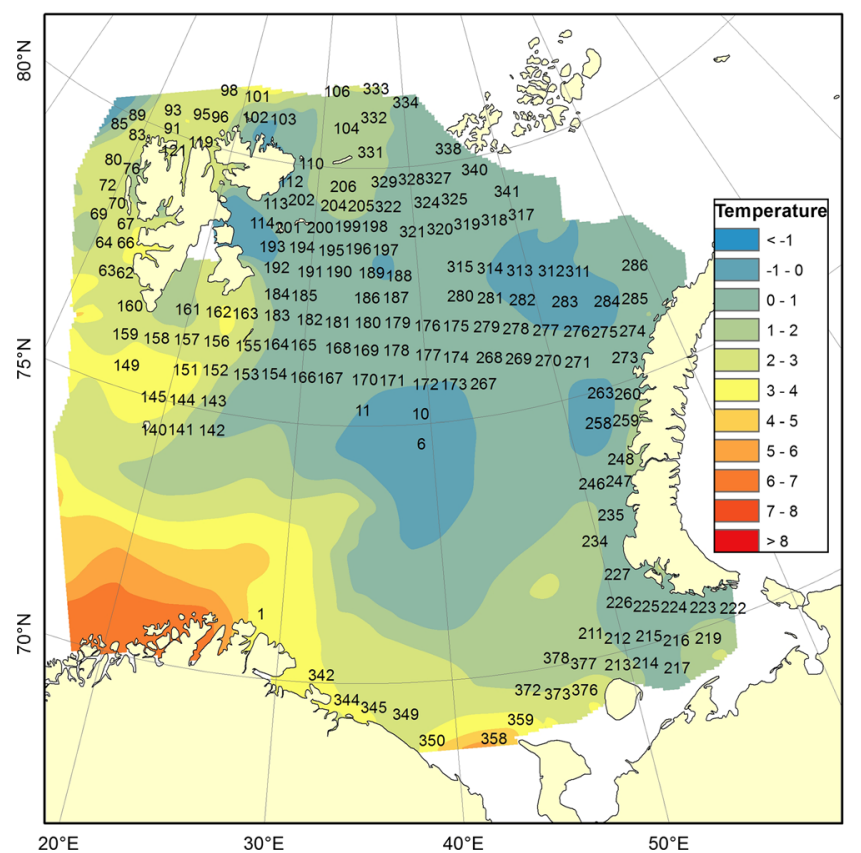

(b)

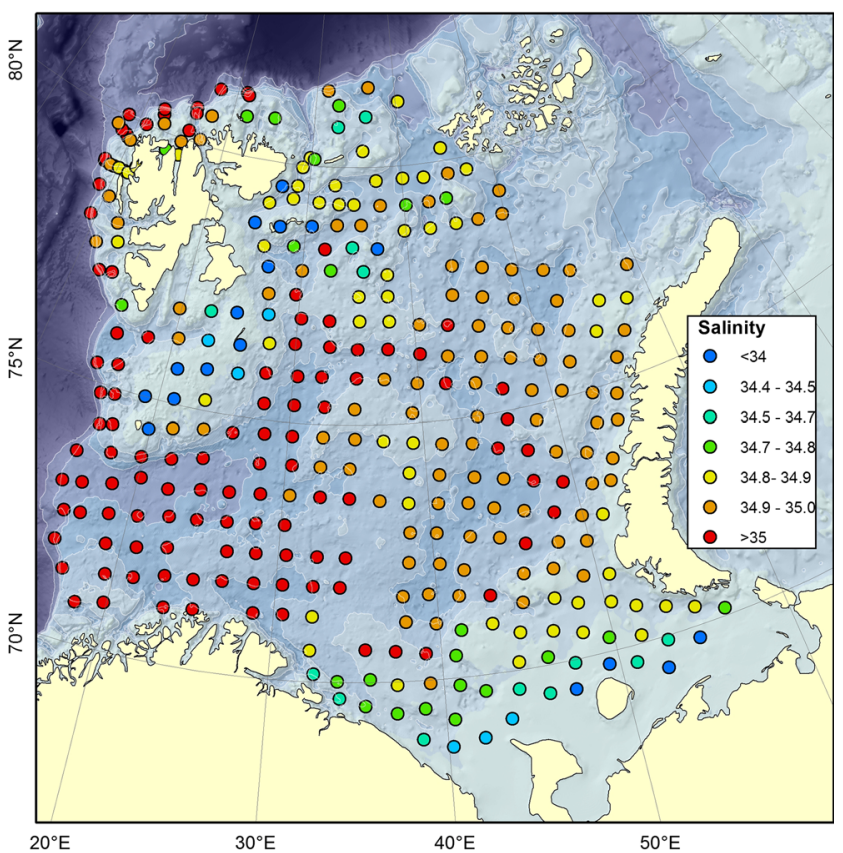

Fig. 2 Haitat variables used in the analysis. a Interpolated bottom temperatures (colour contours) and number of ice days. b Salinity (ppm, circles) and depth contours. The size of each circle is proportional to the salinity at the respective bottom trawl station

establishing the ordinations, but are added afterwards to see how strongly they are associated with the ordination axes.

CoCA quantifies the co-variation by providing a common variance estimate in the two spaces. To test the significance of the common variance, we performed a permutation test, generating a null distribution of this common variance by randomly reordering the stations in one of the data sets, for example the benthos data set. For each of 9999 random permutations, CoCA is reapplied to obtain a value of the common variance, leading to an estimate of the null distribution. The original common variance is then compared to this null distribution. CoCA results are presented in separate plots for the fish and benthos, each with their corresponding display of the stations. The positions of the stations on each ordination axis are then correlated to show the overall level of co-variation between them.

In order to explore the community dissimilarity between stations as a function of their geographical distance, we computed the Jaccard index of dissimilarity for all pairs of stations (Legendre and Legendre 1998) separately for fish and for benthos and compared these to the inter-station distances.

\section{Results}

On average, there were nine (range 2-18) taxa of fish and 25 (range 3-61) taxa of benthos found at each station. Stations with few fish taxa tended to have few benthos taxa as well (Spearman rank correlation $r=0.427$, $p<0.0001)$. Three taxa were much more widespread than the others both in the fish and in the benthos data set. These were the fishes: Atlantic hookear sculpin Artediellus atlanticus (226 stations of the 329 stations), Atlantic cod Gadus morhua (307 stations) and long rough dab Hippoglossoides platessoides (320 stations), and the benthic invertebrates: northern shrimp Pandalus borealis (263 stations), mud star Ctenodiscus crispatus (245 stations) and sevenline shrimp Sabinea septemcarinata (232 stations). The proportion of fishes registered in only one station (9 out of 64) was similar to the proportion for benthos taxa (43 out of 302).

Each species of fish was found on average in $14 \%$ of the stations (median $20 \%$ of stations), whereas the average for benthos was $8 \%$ (median $9 \%$ of stations). The proportion of zeros was higher in the benthos data set than in the fish data set $(0.92$ vs. 0.86). The lower average occurrences and higher proportion of zeros indicate lower overall densities and/or higher catchabilities in the trawl. Smaller spatial ranges could cause more zeros and lower average occurrences of benthos. However, the positive relationship between spatial distance and difference in species composition among the stations (Jaccard distance, Online Resource 2) levelled out at about $400 \mathrm{~km}$ for both fish and benthos, suggesting similar extent of their spatial ranges. Up to that distance, closer stations had more similar species composition. Still neighbouring stations could be 
very different and even have no species in common (dissimilarity $=1$ ). Close stations in the benthos data set were more dissimilar than close stations in the fish data set $(0.7$ vs. 0.5), and benthos levelled out at a higher dissimilarity than fish (0.9 vs. 0.8). The higher dissimilarity between the stations in the benthos data set is due to a higher number of taxa and more zeros in the benthos data set.

\section{Fish and benthos co-variation and relationship with environmental gradients}

Fish and benthos communities co-varied along gradients of temperature/ice presence and depth/salinity (Fig. 3). The common variance accounted, significantly $(p<0.0001$, 10,000 permutations), for $8.3 \%$ of the total variation in fish community structure and $4.5 \%$ in benthos. Of the common variance, $44.9 \%$ was accounted by the first and second CoCA axes (CoCA axis 1: $33.8 \%$, CoCA axis 2: $11.1 \%)$. The respective CoCA axes of fish and benthos were highly correlated (Spearman correlation of fish and benthos axes 1: $r=0.869$, Spearman correlation of fish and benthos axes 2: $r=0.842$ ).

For both fish and benthos, the first common CoCA axis, associated with the temperature gradient, was characterised by a gradient of species from typically Arctic species such as Atlantic poacher Leptagonus decagonus (Fig. 3 fish: Lep.dec) and northern basket star Gorgonocephalus arcticus (Fig. 3 benthos: Gor.arc) to boreal species, such as tusk Brosme brosme (Fig. 3 fish: Bro.bro), and purple heart urchin Spatangus purpureus (Fig. 3 benthos: Spa.pur).

The second common axis, associated with the depth gradient, separated shallow water, bank species such as haddock Melanogrammus aeglefinus (Fig. 3 fish: Mel.aeg) and sculptured shrimp Sclerocrangon boreas (Fig. 3 benthos: Scl.bor) from deeper water species such as beaked redfish Sebastes mentella (Fig. 3 fish: Seb.men) and the amphipod Epimeria loricata (Fig. 3 benthos: Epi.lor).

When mapping the first axes scores for fish and benthos, a strong spatial coherence was apparent (Fig. 4). A largescale gradient of $>1000 \mathrm{~km}$ separated the south-western and north-eastern communities of both fish and benthos. This gradient also separates two regions dominated by different water masses, the Atlantic inflow in the southwest and the Arctic water masses in the north-east (Fig. 1).

The fish-benthos spatial coherence was also prominent when mapping the second axes scores (Fig. 5), separating the bank/shallow water communities from communities found in the deeper troughs and trenches connecting the Barents Sea to the Norwegian Sea in the west, and the polar basin in the north. The CoCA 2 scores had spatial coherence at the scale of hundreds of kilometres.
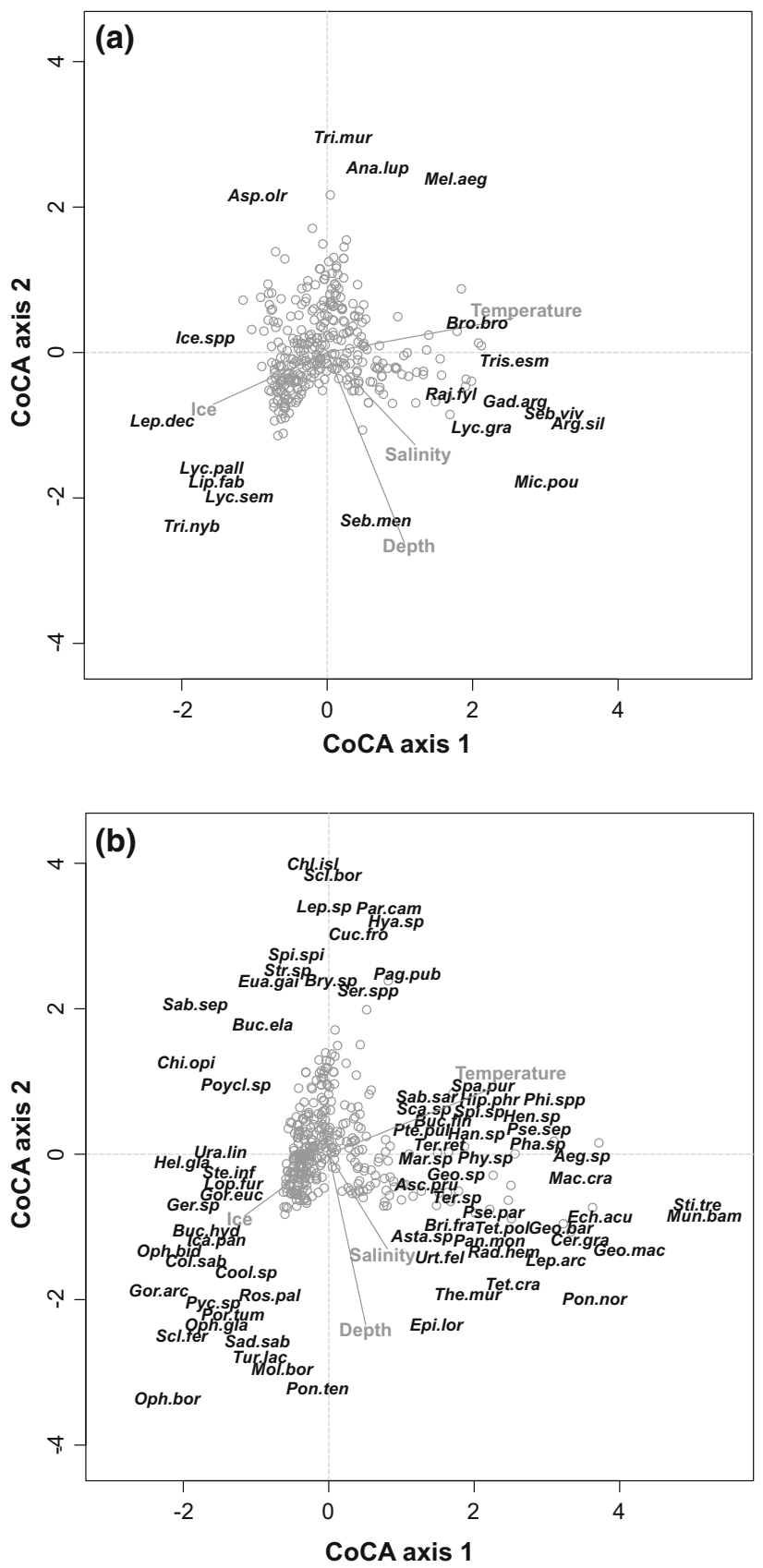

Fig. 3 Corresponding biplots for fish (a, upper) and benthos (b, lower) in the co-correspondence analysis. Of the co-variance between the presence of fish and benthos, $44.9 \%$ is explained by these two ordination axes

\section{Discussion}

The spatial co-variation of demersal fish and megabenthos community data and their relationship to abiotic factors has been analysed. Despite their difference in motility and other ecological traits, the two main gradients in species composition were very similarly for fish and benthos. 
(a)

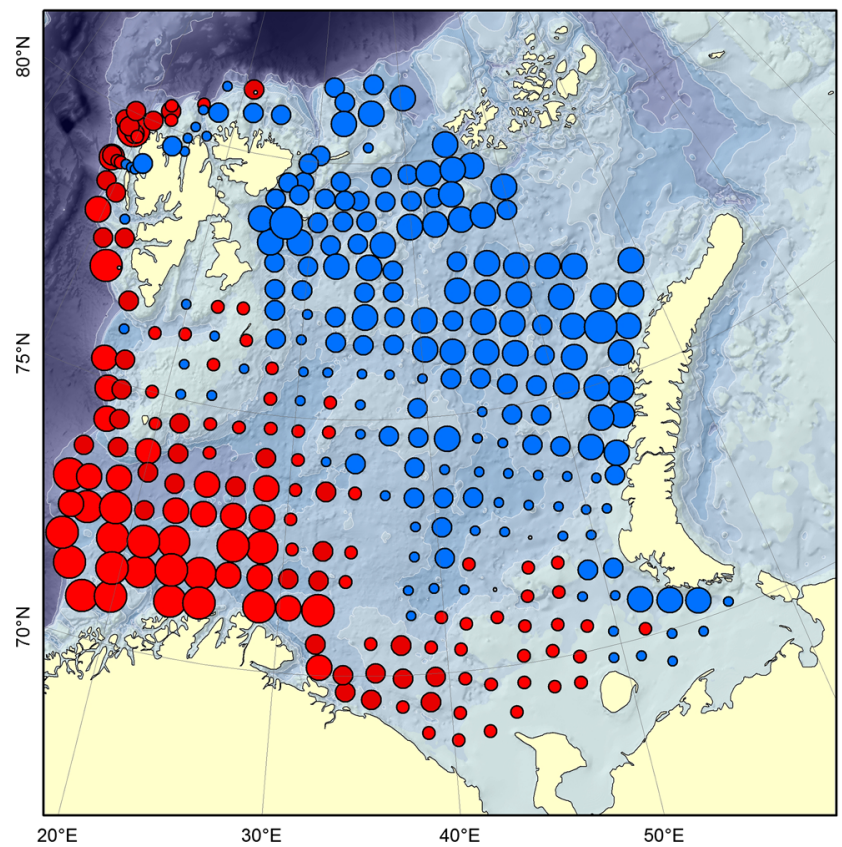

(b)

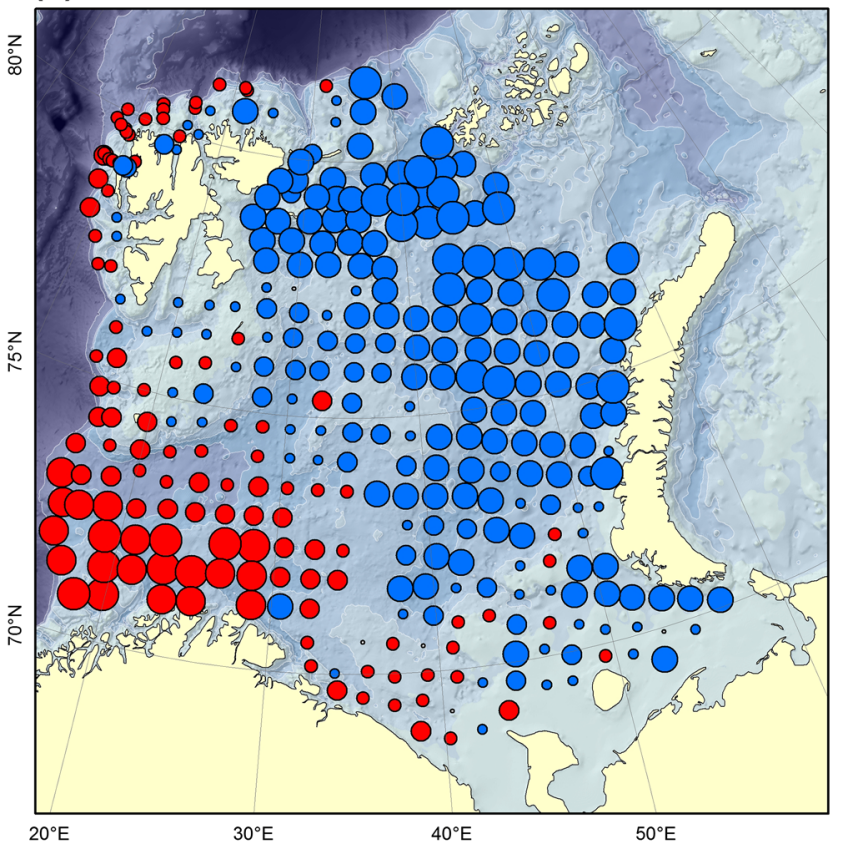

Fig. 4 Site scores of the first common axis of fish $(\mathbf{a}$, left $)$ and benthos $(\mathbf{b}$, right $)$. The size of each circle is proportional to the absolute value of the site score for the respective station; blue circle negative score and red circle positive score

(a)

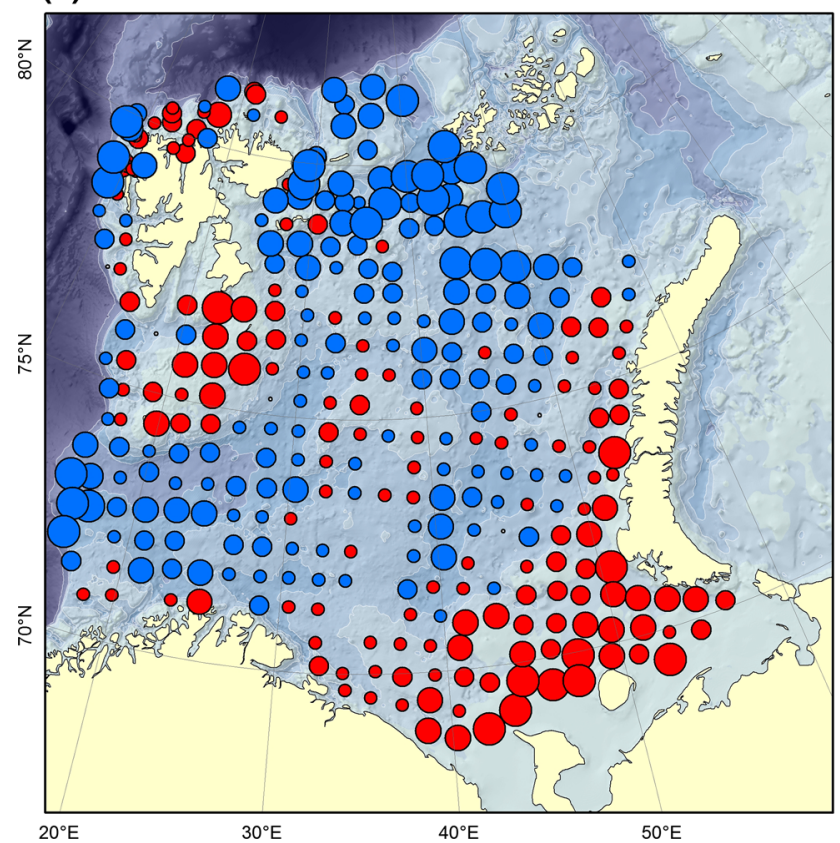

(b)

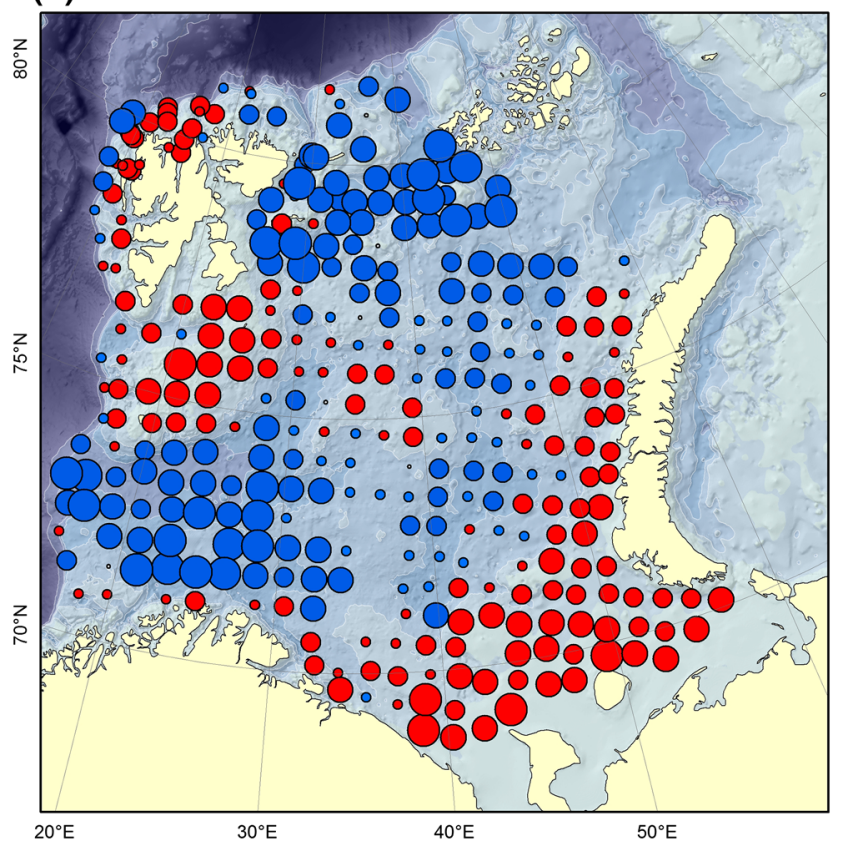

Fig. 5 Site scores of the second common axis of fish $(\mathbf{a}$, left $)$ and benthos $(\mathbf{b}$, right $)$. The size of each circle is proportional to the absolute value of the site score for the respective station; blue circle negative score and red circle positive score 


\section{Temperature and sea ice: Arctic versus boreal communities}

The first CoCA axis separated species in the south-west from species in the north-east. The ice-free, temperate waters in the south-western Barents Sea were characterised by warm-water affinity fish and benthos species that have been classified as boreal or mainly boreal in the literature (Online Resource 1 and references therein). The cold, and seasonally ice-covered water of the northern Barents Sea, was characterised by cold-water affinity species classified as Arctic, arcto-boreal or mainly Arctic species (Online Resource 1). Thus, the main turnover in species composition across the Barents Sea is a zoographical gradient from boreal to Arctic species.

The marine species in the pan-Arctic region originate from the Atlantic or Pacific boreal faunas, but an appreciable amount of endemism has evolved (Briggs 2003). More insight into the phylogenetic histories of different marine groups in the pan-Arctic region has been obtained using DNA barcoding comparing species across the northern hemisphere (e.g. Mecklenburg and Steinke 2015 for fishes). The zoogeographical classifications of the Barents Sea fauna (Online Resource 1) are not directly based on phylogeny, but rather on living and breeding areas relative to the water masses. These classifications are based on the earlier studies on northern marine biogeography that mostly were carried out by Russian scientists (Briggs and Bowen 2012).

Zoogeographical patterns arise from range limits determined by the species' adaptations to their environment (Wiens 2011). These adaptations define the ecological niches of the species. The spatial patterns and relationships to the environment are maintained by the failure to adapt to unsuitable conditions (niche conservatisms) (Wiens 2011). The distribution of the water masses, ice and other variables defining the Arctic and boreal habitat and the niche conservatism of the boreal and Arctic species maintain the large-scale patterns detected here even in the absence of clear barriers to dispersal.

\section{Depth and salinity}

The second CoCA axis separated bank species from deeper water species. In the Barents Sea, higher salinity water is found in the deeper trenches and troughs and fresher water is found on the banks (Fig. 2b). Sediment type is another potentially important abiotic factor that we have not considered due to lack of adequate data. Sediment also correlates with depth with finer sediments in deeper areas. Depth, salinity and sediment could all be contributing factors resulting in the species turnover along the second CoCA axis.
Among the few other studies addressing fish and benthos spatial co-variation, Gaertner et al. (1999), Colloca et al. (2003) and Sell and Kröncke (2013) found the composition of demersal fish to correlate significantly with the composition of the ambient epifauna. These studies were at a much smaller scale than the present study. In these studies, bottom depth was the main structuring factor for both demersal fish and benthic communities.

\section{The effect of scale}

Ecological processes are scale dependent (Wiens 1989). The environment influences species composition at different spatial scales, from small-scale habitat heterogeneity to large-scale climatic forcing and gradients. The spatial extent of the study will often determine the relative importance of the habitat variables in a study. For example, in another study encompassing a whole shelf ecosystem (the North Sea), temperature was found to be the most important factor for the demersal community (Reiss et al. 2010). On a smaller scale within the North Sea, at the Dogger Bank, depth was found to be the most important factor (Sell and Kröncke 2013).

The standard inter-station distance (grain size) of our study was $65 \mathrm{~km}$, so we could not detect heterogeneity at scales below this distance. Many of the processes such as predator-prey interactions, patchiness caused by modular growth, movement of small, less motile animals and passive dispersal of juvenile stages of sessile animals are taking place at smaller spatial scales than the grain size of our study. For instance, evidence of predator-prey interactions structuring the spatial relationships between fish and benthos communities has been found on scales of a few kilometres (Sell and Kröncke 2013), a scale smaller than the grain size of our study. We found that the dissimilarities in species composition levelled off at the same distance $(\sim 400 \mathrm{~km})$ for fish and benthos, suggesting that the study was too coarse to detect spatial differences in species composition between fish and benthos due to differences in motility and other ecological traits.

\section{Spatial variation in fish and benthos interactions}

We calculated that only $11 \%$ of the benthos species in our data set was recorded as prey of the fishes in our study (Online Resource 1). This calculation was based on a recently updated food web topology for the Barents Sea (Planque et al. 2014, updated August 2015). Benthos-fish interactions in the Barents Sea are important, and around $80 \%$ of the demersal fishes in the Barents Sea are benthivorous (Wiedmann et al. 2014; see also Dolgov et al. 2011a, b; Online Resource 1), so the main reason is that our sampling trawl is not efficient in catching smaller benthic 
species that are more common as fish prey. In addition, benthos form habitat for fish (below), might feed on fish egg and larvae and compete with fish for food (Dolgov et al. 2011b). From the spatial variation in functional traits (size, motility, feeding types, etc.) of the fishes (Wiedmann et al. 2014) and benthos species (Jørgensen et al. 2015 and below), we can infer how the nature of the fish and benthos interactions varies in space and contributes to the observed spatial co-variation.

In deeper areas in the Barents Sea, with relative warm, saline waters, the large-bodied Geodia barretti and $G$. macandrewii are forming dense populations referred to as "sponge ground". The fauna associated with sponge grounds is estimated to be at least twice as rich as that of the surrounding gravel or soft bottoms (Bett and Rice 1992; Klitgaard 1995) and sponge grounds may therefore have functions similar to those of coral reefs. Fish species such as Sebastes spp. is frequently observed here, and both Geodia spp. and Sebastes spp. are highly contributing species in the deep, saline waters in the present study. The characterising co-varying fish and benthos species do not form feeding links (Online Resource 1), but benthos probably act as important habitat for fishes in the deeper areas with sponge grounds.

On the shallow banks, feeding interactions between the studied megabenthos and demersal fishes were more common. Both haddock and the Atlantic wolffish (Anarhichas lupus) were characteristic species for the shallow and fresh bank areas. These species include a large proportion of benthos in their diet (Dolgov et al. 2011a, b). They also included several of the megabenthos in our data set in their diet (haddock: 26 taxa, Atlantic wolffish: 10 taxa, Online Resource 1). On the banks where haddock and Atlantic wolffish are commonly found, they co-occurred with the area characteristic megabenthic prey taxa such as the crab Hyas sp., the crangonid crustacean Sabinea sp., sea urchins Strongylocentrotus sp., the Cirripedia Balanus sp., the sea cucumber Cucumaria frondosa and the bivalve Chlamys islandica. These prey species have been recorded in the diet of haddock and Atlantic wolffish (Online Resource 1).

The cold and seasonally ice-covered water of the northern Barents Sea was characterised by large-bodied megabenthic species including the basket stars G. arcticus and G. eucnemis, the giant sea spider Colossendeis sp., the large Crangonidae crustacean Sclerocrangon ferox and the large isopod Saduria sabini. These are not prey of the cooccurring fish species (Online Resource 1). The characterising fishes in the Arctic waters were mainly smallbodied stationary fishes with benthivore life modes, such as big eye sculpin (Triglops nybelini) and different eelpouts, such as Lycodes pallidus and L. seminudus. Although many of these fishes feed on benthos, they feed on mainly smaller benthos species that are poorly sampled by our trawl, e.g. gammarid amphipods, small bivalves and polychaetes (Dolgov 2014).

\section{Implications for the Barents Sea food web structure and prospects for further studies}

The large-scale co-variation in fish and benthos community composition, associated with varying temperature and ice conditions, indicates distinct biogeographical patterns across several functional groups in the Barents Sea ecosystem. In addition to temperature tolerance, some of the niche characteristics that distinguish boreal vs. Arctic species, such as diet width (boreal generalists vs. Arctic specialists, Kortsch et al. 2015), are adaptations to the different environmental conditions that help explain biogeographical patterns. At the same time, these niche characteristics have also important implications for food web organisation in that Arctic communities display more modular and less connected food webs than boreal ones, because they lack generalists (Kortsch et al. 2015).

The Barents Sea is currently warming due to climate change, and boreal fish species are moving north (Fossheim et al. 2015). Changes in fish distributions in the Arctic region have been found to be faster than predicted from models (Fossheim et al. 2015; Ingvaldsen et al. 2015; Christiansen et al. 2016). The distributional changes are causing reconfigurations of ecological interactions in the Arctic (Kortsch et al. 2015). As the Barents Sea continues to warm, the large-scale patterns detected in this study, the interactions between fish and benthos as well as the food web structure are expected to change. Currently, changes in species distributions, interactions and food web structure in the Arctic cannot be predicted by models and data from regular large-scale surveys like the one used here are needed (e.g. Ingvaldsen et al. 2015; Christiansen et al. 2016).

Acknowledgements We thank all the staff that participated on and helped organising the joint Norwegian-Russian Ecosystem survey. The work by E.J., L.L.J., M.F., R.P. and M.G. was made possible by the Norwegian Research Council project "BarEcoRe" (2009-2013, NRC contract number 200793/S30).

Open Access This article is distributed under the terms of the Creative Commons Attribution 4.0 International License (http://creati vecommons.org/licenses/by/4.0/), which permits unrestricted use, distribution, and reproduction in any medium, provided you give appropriate credit to the original author(s) and the source, provide a link to the Creative Commons license, and indicate if changes were made.

\section{References}

Andriashev AP, Chernova NV (1995) Annotated list of fishlike vertebrates and fishes of the Arctic Seas and adjacent waters. J Icthyol 34:435-456 
Anisimova NA, Jørgensen LL, Ljubin PA, Manushin IE (2011) Benthos. In: Jakobsen T, Ozhigin VK (eds) The Barents Seaecosystem, resources and management. Half a century of Russian-Norwegian cooperation. Tapir Academic Press, Trondheim, pp 121-160

Anon (2011) Survey report from the joint Norwegian/Russian ecosystem survey in the Barents Sea August-October 2011. IMR/PINRO Joint Report Series, No. 3/2011

Bett BJ, Rice AL (1992) The influence of hexactinellid sponge (Pheronema carpenteri) spicules on the patchy distribution of macrobenthos in the Porcupine Seabight (bathyal NE Atlantic). Ophelia 36:217-226

Briggs JC (2003) Marine centres of origin as evolutionary engines. J Biogeogr 30:1-18

Briggs JC, Bowen BW (2012) A realignment of marine biogeographic provinces with particular reference to fish distributions. J Biogeogr 39:12-30

Buzhinskaja GN (2010) Illustrated keys to free-living invertebrates of Eurasian Arctic seas and adjacent deep waters. In: Sirenko BI (ed) Nemertea, Cephalorincha, Oligochaeta, Hirudinea, Pogonophora, Echiura, Sipuncula, Phoronida and Brachiopoda, 2. University of Alaska Fairbanks, KMK Scientific Press Ltd, Alaska

Christiansen JS, Bonsdorff E, Byrkjedal I, Fevolden SE, Karamushko OV, Lynghammar A, Mecklenburg CW, Møller PDR, Nielsen J, Nordström MC, Præbel K, Wienerroither RM (2016) Novel biodiversity baselines outpace models of fish distribution in Arctic waters. Sci Nat 103:1-6

Cochrane SKJ, Pearson TH, Greenacre M, Costelloe J, Ellingsen IH, Dahle S, Gulliksen B (2012) Benthic fauna and functional traits along a Polar Front transect in the Barents Sea-advancing tools for ecosystem-scale assessments. J Mar Syst 94:204-217

Colloca F, Cardinale M, Belluscio A, Ardizzone G (2003) Patterns of distribution and diversity of demersal assemblages in the central Mediterranean Sea. Estuar Coast Shelf Sci 56:469-480

Cornell HV, Harrison SP (2013) Regional effects as important determinants of local diversity in both marine and terrestrial systems. Oikos 122:288-297

Dalpadado P, Arrigo KR, Hjøllo SS, Rey F, Ingvaldsen RB, Sperfeld E, van Dijken GL, Stige LC, Olsen A, Ottersen G (2014) Productivity in the Barents Sea-response to recent climate variability. PLoS One. doi:10.1371/journal.pone.0095273

Dolgov AV (2014) Diet of non-target fishes in the northern Barents Sea. In: Karasev AB, Ozhigin VK, Yaragina NA (eds) Peculiarities of biological productivity in the northern parts of the Barents Sea under warming in Arctic. PINRO Press, Murmansk (in Russian)

Dolgov AV, Johannesen E, Høines $\AA$ (2011a) Main species and ecological importance. Half a century of Russian-Norwegian cooperation. In: Jakobsen T, Ozhigin VK (eds) The Barents Sea-ecosystem, resources and management. Tapir Academic Press, Trondheim, pp 193-200

Dolgov AV, Johannesen E, Bogstad B (2011b) Benthivorous fish. In: Jakobsen T, Ozhigin VK (eds) The Barents Sea-ecosystem, resources and management. Half a century of Russian-Norwegian cooperation. Tapir Academic Press, Trondheim, pp 455-459

Fossheim M, Primicerio R, Johannesen E, Ingvaldsen RB, Aschan M, Dolgov AV (2015) Recent warming leads to a rapid borealization of fish communities in the Arctic. Nat Clim Change 5:673-677

Gaertner JC, Mazouni N, Sabatier R, Millet B (1999) Spatial structure and habitat associations of demersal assemblages in the Gulf of Lions: a multicompartment approach. Mar Biol 135:199-208

Greenacre M (2013a) The contributions of rare objects in correspondence analysis. Ecology 94:241-249
Greenacre M (2013b) Contribution biplots. J Comput Graph Stat 22:107-122

Ingvaldsen RB, Bogstad B, Dolgov AV, Ellingensen KE, Gjøsæter H, Gradinger R, Johannesen E, Tveraa T, Yoccoz NG (2015) Sources of uncertainties in cod distribution models. Nat Clim Change 5:788-789

Johannesen E, Høines ÅS, Dolgov AV, Fossheim M (2012) Demersal fish assemblages and spatial diversity patterns in the ArcticAtlantic transition zone in the Barents Sea. PLoS One 7(4):e34924. doi:10.1371/journal.pone.0034924

Jørgensen LL, Ljubin P, Skjoldal HR, Ingvaldsen RB, Anisimova N, Manushin I (2015) Distribution of benthic megafauna in the Barents Sea: baseline for an ecosystem approach to management. ICES J Mar Sci 72:595-613

Klitgaard AB (1995) The fauna associated with outer shelf and upper slope sponges (Porifera, Demospongiae) at the Faroe Islands, northeastern Atlantic. Sarsia 80:1-22

Kortsch S, Primicerio R, Fossheim M, Dolgov A, Aschan M (2015) Climate change alters the structure of Arctic marine food webs due to poleward shifts of boreal generalists. Proc R Soc B 282:20151546

Legendre P, Legendre L (1998) Numerical ecology. Elsevier, Amsterdam

Maslanik J, Stroeve J (1999) Near-real-time DMSP SSM/I-SSMIS daily Polar Gridded Sea-Ice concentrations, 2008-2009. National Snow and Ice Centre. Digital media, Boulder

Mecklenburg CM, Steinke D (2015) Ichthyfaunal baselines in the Pacific Arctic region and RUSALCA Study Area. Oceanography 28:158-189

Mecklenburg CM, Byrkjedal I, Christiansen JS, Karamushko OV, Lynghammar A, Møller PR (2013) List of marine fishes of the Arctic region annotated with common names and zoogeographic characterizations. Conservation of Arctic Flora and Fauna, Akureyri

Meier W, Fetterer F, Knowles K, Savoie M, Brodzik MJ (2006) Updated quarterly. Sea-ice concentrations from Nimbus-7 SMMR and DMSP SSM/I Passive Microwave Data, 1978-2007. National Snow and Ice Data Center. Digital media, Boulder

Michalsen K, Dalpadado P, Eriksen E, Gjøsæter H, Ingvaldsen RB, Johannesen E, Jørgensen LL, Knutsen T, Prozorkevich D, SkernMauritzen M (2013) Eight years of ecosystem surveys in the Barents Sea-review and recommendations. Mar Biol Res 9:932-947

Planque B, Primicerio R, Michalsen K, Aschan M, Certain G, Dalpadado P, Gjøsæter H, Hansen C, Johannesen E, Jørgensen LL, Kolsum I, Kortsch S, Leclerc L-M, Omli L, SkernMauritzen M, Wiedemann M (2014) Who eats whom in the Barents Sea: a food web topology from plankton to whales. Ecology 95:1430

Reiss H, Degraer S, Duineveld GCA, Kröncke I, Aldridge J, Craeymeersch JA, Eggleton JD, Hillewaert H, Lavaleye MSS, Moll A, Pohlmann T, Rachor E, Robertson M, Vanden Berghe E, van Hoey G, Rees HL (2010) Spatial patterns of infauna, epifauna, and demersal fish communities in the North Sea. ICES J Mar Sci 67:278-293

Sell A, Kröncke I (2013) Correlations between benthic habitats and demersal assemblages - a case study on the Dogger Bank (North Sea). J Sea Res 8:12-24

Sirenko BI (2004) Fauna and ecosystems of the Laptev Sea and adjacent deep waters of the Arctic Basin. Part II. Explorations of the fauna of the Seas 54. Zoological Institute RAS, St. Petersburg

Sirenko BI (2009) Ecosystem and biological resources of the Chukchi Sea and adjacent waters. Explorations of the fauna of the Seas 64. Zoological Institute RAS, St. Petersburg 
Sirenko BI, Denisenko SG (2010) Fauna of the East Siberian Sea, distribution patterns and structure of bottom communities. Explorations of the fauna of the Seas 66. Zoological Institute RAS, St. Petersburg

Stapanjants SD (2012) Illustrated keys to free-living invertebrates of Eurasian Arctic seas and adjacent deep waters. In: Sirenko BI (ed) Cnidaria, Ctenophora. Alaska Sea Grant. University of Alaska Fairbanks, KMK Scientific Press Ltd USA, Alaska

ter Braak CJF (2004) Co-correspondence analysis: a new ordination method to relate two community compositions. Ecology 85:834-846

Vasilenko SV, Petryachov VV (2009) Illustrated keys to free-living invertebrates of Eurasian Arctic Seas and Adjacent deep waters. In: Sirenko BI (ed) Rotifera, Pycnogonida, Cirripedia, Leptostraca, Mysidacea, Hyperiidea, Caprellidea, Euphausiacea,
Dendrobranchiata, Pleocyemata, Anomura, and Brachyura. BAlaska Sea Grant. University of Alaska Fairbanks, KMK Scientific Press Ltd, Alaska

Wiedmann MA, Aschan M, Certain G, Dolgov AV, Greenacre M, Johannesen E, Planque B, Primicerio R (2014) Functional diversity of the Barents Sea fish community. Mar Ecol Prog Ser 495:205-218

Wienerroither R, Johannesen E, Dolgov AV, Byrkjedal I, Bjelland O, Drevetnyak K, Eriksen KB, Høines A, Langhelle G, Langøy H, Prokhorova T, Prozorkevich D, Wenneck T (2011) Atlas of the Barents Sea fishes. IMR/PINRO joint report series 1-2011

Wiens JA (1989) Spatial scaling in ecology. Funct Ecol 3:385-397

Wiens JA (2011) The niche, biogeography and species interactions. Philos Trans R Soc B 366:2336-2350 